INDEPENDENT JOURNAL OF MANAGEMENT \& PRODUCTION (IJM\&P)

http://www.ijmp.jor.br

v. 5, n. 4, October - December 2014

ISSN: 2236-269X

DOI: 10.14807/ijmp.v5i4.223

\title{
ESTIMATION OF THE INFORMAL ECONOMY: AN APPLICATION OF FUZZY SETS
}

Vinícius Ximenes Provenzano

IBMEC, Brazil

E-mail: viniciusxp@gmail.com

Walter Gassenferth IBMEC, Brazil

E-mail: walterg@quantiac.com

Maria Augusta Soares Machado

IBMEC, Brazil

E-mail: mmachado@ibmecrj.br

Submission: $22 / 04 / 2014$

Revision: 10/05/2014

Accept: 24/05/2014

\section{ABSTRACT}

Data on "Informal Economy" magnitudes are relevant for the establishment of adequate micro and macroeconomics but, there are very few indicators in this respect. The goal of this paper is to generate a temporal series that would describe the informal economy in Brazil. For this purpose fuzzy logic was used. The input variables were a degree of economic opening as well as the tax load rate in relation to GNP (Grow National Product).

Keywords: informal economy, fuzzy logic, estimation 


\section{INTRODUCTION}

Data on the size of the global economy of any country or bloc, and their economic indicators are the result of the study and calculation of statistics, on trade, production and investment of the object of study. But there is one part of the economy that is not captured by economic indicators and has long been considered of little relevance to the formation of the economy in toto, this part is commonly called the Informal Economy.

But there is much discussion about the accuracy of economic indicators of this phenomenon. The very definition of the informal economy is also discussed, which makes it more difficult to measure it. The importance of having a measure of the informal economy is also measure the effectiveness of measures taken to fight it and not stimulate their growth, thus generating an increase in government revenue and benefits to society as a whole.

The theory of fuzzy sets, an extension of the classical theory of sets, has been shown effective in many different fields with data using subjective criteria. Using this tool for the economy is still little explored, and the need to find a good measure for the informal economy appears as a fertile field for experimentation. Draeseke and Giles (2002) made the case for New Zealand.

The objective of this paper is to generate an annual series that describes the informal economy in Brazil for the period studied.

Fuzzy sets were used as a theory tool. It is part of the informal economy that all economic activity that is outside or legality of the tax. Fraudulent activities, smuggling and drug trafficking are part of the informal economy as much as the omission of income, rent irregular rent or exchange of goods and services.

\section{FUZZY SETS}

The theory of Fuzzy Sets was developed by electronics engineer Zadeh (1975), professor at the University of California. In the 70's began to be widely adopted mainly in the areas of data classification, expert systems, decision analysis, robotics, pattern recognition and time series forecasting. 
DOI: 10.14807/ijmp.v5i4.223

For example, the phrase "high unemployment" can be interpreted in many different ways depending on the situation. In Sweden, where the unemployment rate used to be $3 \%$, can be interpreted as a high unemployment rate any higher than $5 \%$. In other countries, however, the unemployment rate cannot be considered high unless it exceeds $10 \%$. In terms of fuzzy logic, "high unemployment", as it is called a subjective category.

In contrast to conventional probability theory, the theory of fuzzy sets uses language to describe the uncertainty in the real world. Thus allows the use of linguistic expressions such as "Brazil has a high level of unemployment," and assign degrees of membership.

The degrees of membership values are intermediate between the values of true (0) and fake (1) in traditional Boolean logic. In fact, the Boolean logic is a particular case of fuzzy logic, the case in which the degrees of relevance are the extremes. The degrees of membership are assigned through a membership function.

Fuzzy Reasoning or approximate reasoning is an inference procedure that derives conclusions of a set of fuzzy if-then rules of known facts.

The knowledge of the phenomenon is expressed through statements like: "if (a set condition is satisfied) then (we can infer a set of consequences)" (OLIVEIRA et al. 2007).

\section{METHODOLOGY}

The use of fuzzy set theory as a tool in economics is still very small. Draeseke and Giles (2002) propose its use to measure the degree of informality in the economy. The hypothesis that motivates this work is the ability to measure the informal economy, an unobservable variable of the economy through two entrances. The method of approach is deductive and it is a case study in Brazil.

The proposed technique is based on Mamdani Fuzzy Inference System.

This paper aims to produce an experimental quantitative research as having premised on the existence of a causal relationship between variables. The samples were obtained from official data released by the IBGE and the frequency of time series is annual. 
DOI: 10.14807/ijmp.v5i4.223

The first observation of each series is about the year 1974 and the last to 2002, totaling a period of 28 years.

Draeseke and Giles (2002) had used as input variables in their fuzzy inference system the degree of regulation of the economy and taxes. In Brazil there is not an index that accurately captures the degree of regulation of the economy. It was chosen, then use as a proxy for the degree of regulation of the economy to build an index of openness. It is considered that the higher the level of regulation of the economy, the lower the degree of opening. To construct the index of openness it was used the ration between the sum of the country's exports and imports to GDP.

The first step was to obtain the following time series between 1974 and 2002:

- Exports

- imports

- GDP

- Total Gross Tax (\% GDP)

From the first three series it was generated the index of the degree of openness of the first input variable. The total tax is the second input variable.

The following charts present the series that were used to obtain the first input variable.

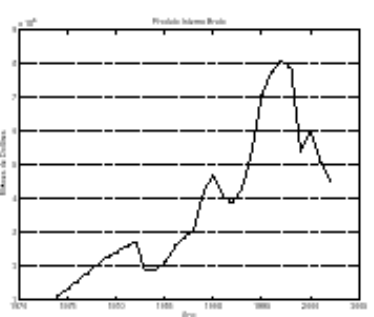

(a) PIB

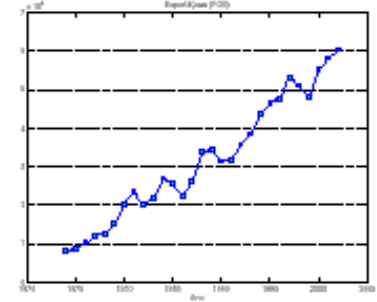

(c) Exportações

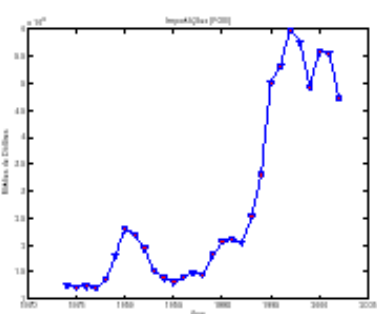

(b) Importações

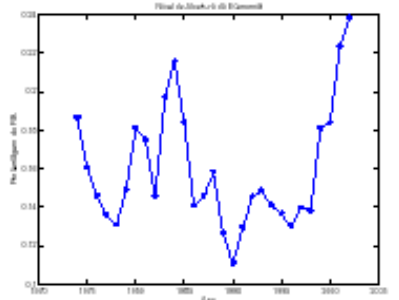

(d) Abertura da Economia

Figure 1: GNP (a), Imports (b) , Exports (c) , d) Total Gross Tax (\% GDP) :19742002 
DOI: 10.14807/ijmp.v5i4.223

Next graph presents tax load rate in relation to GNP (Grow National Product).

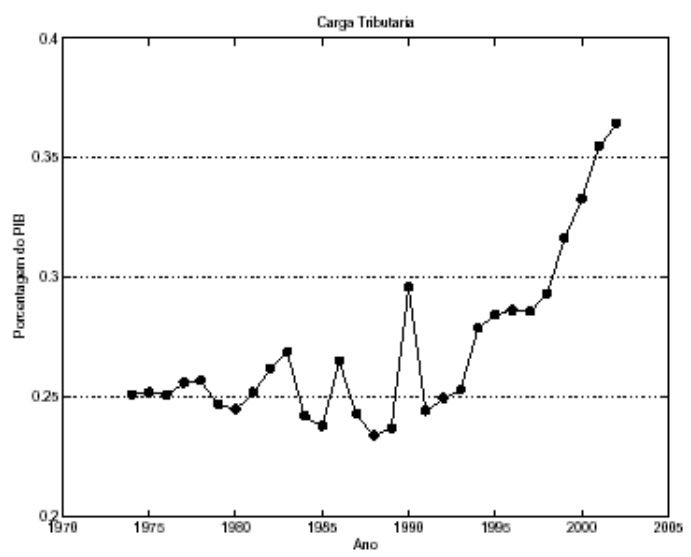

Figure 2: tax load rate in relation to GNP (Grow National Product)

Each of the input variables was modeled with five membership functions, according to its degree of magnitude.

Thus both the variable opening of economy as variable Tax were modeled with the following membership functions: . Very Low, Low, Normal, High and Very High.

Trials were made on the modeling of input variables using triangular , Gaussian and Sigmoid membership functions.

The rule base used in this paper was that proposed by Draeseke and Giles (2002).

Removing the weights proposed by Draeseke and Giles, one can obtain a new rule base. The option of having two sets of rules reinforces the experimental feature of this paper, to compare the results obtained using two sets of rules. The first basic rule is called Heavy Rule Base and the second Not Heavy Rule Base. Then it is created a new table containing the new rule base, where the only change from the previous table is that all rules have the same weight of 1 . As the input variables, the output variable, informal economy is modeled with five membership functions also called: Very Low, Low, Medium, High, Very High. It were used Gaussian membership functions to model the output variable.

The rules are shown in table 1. 
INDEPENDENT JOURNAL OF MANAGEMENT \& PRODUCTION (IJM\&P)

http://www.ijmp.jor.br

v. 5, n. 4, October - December 2014

ISSN: 2236-269X

DOI: 10.14807/ijmp.v5i4.223

Table 1- rule base used in this paper

\begin{tabular}{cccc}
\hline Openness of economy & Tax burden & Level of informality & Weigh \\
\hline Very high & Very high & Very high & 1 \\
\hline Very high & High & Very high & 0.8 \\
\hline Very high & Normal & Low & 1 \\
\hline Very high & Low & Low & 0.8 \\
\hline Very high & Very Low & Medium & 0.8 \\
\hline High & Very high & Very high & 1 \\
\hline High & High & High & 1 \\
\hline High & Normal & High & 0.8 \\
\hline High & Low & Medium & 1 \\
\hline High & Very Low & Medium & 1 \\
\hline Medium & Very high & High & 1 \\
\hline Medium & High & High & 0.8 \\
\hline Medium & Normal & Medium & 1 \\
\hline Medium & Low & Low & 0.8 \\
\hline Medium & Very Low & Low & 1 \\
\hline Low & Very high & High & 1 \\
\hline Low & High & Medium & 1 \\
\hline Low & Normal & Low & 0.8 \\
\hline Low & Low & Low & 1 \\
\hline Low & Very Low & Very Low & 1 \\
\hline Very Low & Very high & Medium & 0.8 \\
\hline Very Low & High & Low & 0.8 \\
\hline Very Low & Normal & Low & 1 \\
\hline Very Low & Low & Very Low & 0.8 \\
\hline Very Low & Very Low & Very Low & 1 \\
\hline & & &
\end{tabular}

\section{RESULTS AND CONCLUSIONS}

Analyzing the graphs modeled using triangular and Gaussian membership functions it can be seen that there is not a difference between the two series (using unitary and different weights).

It can be seen in Figures 3 and 4 that when using triangular membership functions the informal economy decreases from 4 (1974) to 1 (1980) and grows a little bit in 2000th but dacays after, it can be said that it is stable around 5 during all 28 years and when using Gaussian membership functions the informal economy is a constant with value 15 from 1974 to 2004 . 
DOI: 10.14807/ijmp.v5i4.223

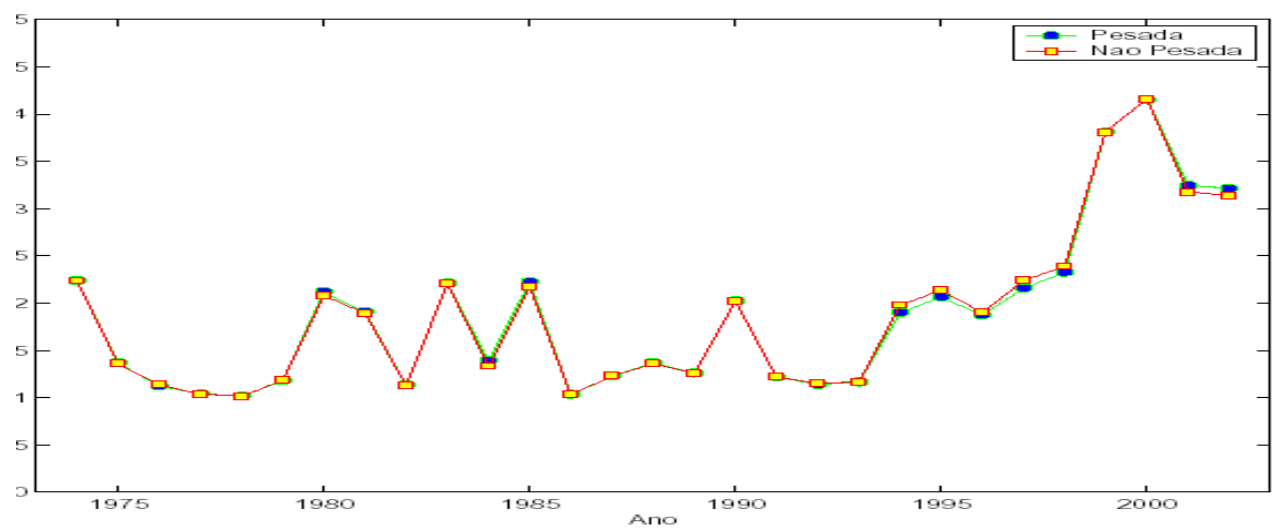

Figure 3: Informal Economy modeled using triangular membership functions

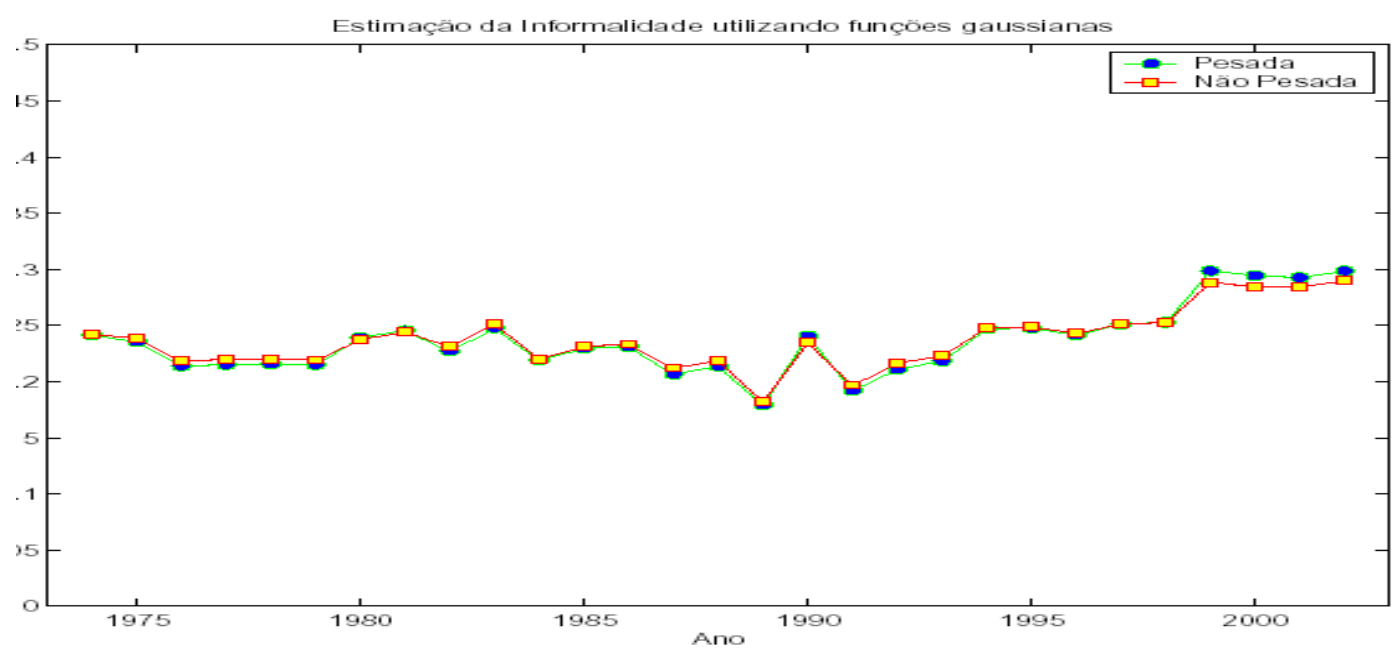

Figure 4: Informal Economy modeled using Gaussian membership functions

For other kind of membership functions (sigmoid and trapezoid) the values are near to the Gaussian.

It has been done non parametric statistics tests to verify if there exists differences between these obtained values and the conclusion was that there exist statistical differences with $95 \%$ of confidence.

This work may be used as a starting point for improving the method of Measurement of the Informal Economy. The addition of new input variables, for example, the unemployment rate and an extension of the rule base for the inclusion of new variables can show relevant results. Another search is being done using an econometric study for the most relevant variables and then rewrite a new rules base to compare with these results.

According to the Brazilian Institute of Geography and Statistics (IBGE), Brazil were more than 10 million urban informal enterprises in 2003, and moved over 17 
DOI: 10.14807/ijmp.v5i4.223

billion dollars. The number corresponds to more than half of all microenterprises in Brazil.

This kind of economy is directly linked to the Gross Domestic Product of the country, because many goods are sold and obtained without taxes payments. To get an idea if everything was formalized in Brazil, our GDP would be $30 \%$ greater than it is today.

According to Holanda (2012), between 2006 and 2011, informal economy has fallen from $20.2 \%$ to $17 \%$ " in large part, this decline is explained by the significant increase in the formal labor market in recent years, a consequence of the good performance of the Brazilian economy in the period, even during the 2009 crisis ".

\section{REFERENCES}

BAJDA, C.(1997) Estimates of underground economy in Australia. School of Economics Discussion Paper

BHATTACHARYYA, D. K. (1999) On the Economic Rationale of Estimating the Hidden Economy. The Economic Journal, n. 456

BLADES, D. (1982) The hidden economy and the national accounts. OECD (Occasional Studies), Paris, p. 28-44

BRAGA, M. J. F.; BARRETO, J. M.; MACHADO, M. A. S.(1995) Conceitos de Matemática Nebulosa na Análise de Risco. Rio de Janeiro: Artes \& Rabiscos

CAGAN, P. (1958) The demand for currency relative to the total money supply. Journal of Political Economy, Brandstaetter, Hermann, n. 66, p. 302-328, Springer

DRAESEKE, R.; GILES, D. E. (2002) A Fuzzy Logic Approach to Modelling the New Zealand underground Economy. Mathematics and Computers in Simulation, v. 59 , p. $115-123$

FEIGE, E. L. (1994) The Underground Economy and the Currency Enigma.

Supplement to Public Finance - Finances Publiques, n. 49, p. 119-136.

GUTMANN, P. M. (1977) The Subterranean Economy. Financial Analysts Journal,n. 34, p. 24-27, Springer.

BARBOSA F. H. F. (2012) Valor Econômico

KAUFMANN, A.; GUPTA, M. M. (1998) Introduction to Fuzzy Mathematical

Models in Engeneering and Management Science. Holanda: North.

LINDSTRÖM, T. (1998) A Fuzzy Design of the Willingness to Invest in Sweden, Journal of Economic Behaviour \& Organization, v. 36, p. 1-17.

OLIVEIRA, H.; CALDEIRA, A.; MACHADO, M.A; SOUZA, R.; TANSCHEIT, R.(2007) Inteligência Computacional Aplicada à Administração, Economia e Engenharia em Matlab. Editora Thomson 
INDEPENDENT JOURNAL OF MANAGEMENT \& PRODUCTION (IJM\&P)

http://www.ijmp.jor.br

v. 5, n. 4, October - December 2014

ISSN: 2236-269X

DOI: 10.14807/ijmp.v5i4.223

ZADEH, L. A. (1975) The concept of a linguistic variable and its application to approximate reasoning,part iii. IEEE Transactions on Systems, Man and Cybernetics, n. 9, p. 43-80 